\title{
Predicting factors of positive orientation and attitudes towards nursing: A quantitative cross-sectional study
}

\author{
Yvonne ten Hoeve ${ }^{\mathrm{a}, *}$, Stynke Castelein ${ }^{\mathrm{b}}$, Wiebren Jansen ${ }^{\mathrm{c}}$, Gerard Jansen ${ }^{\mathrm{d}}$, Petrie Roodbol ${ }^{\mathrm{a}}$ \\ ${ }^{a}$ UMCG School of Nursing and Health, University of Groningen, University Medical Center Groningen, P.O. Box 30.001, 9700 RB Groningen, The Netherlands \\ b Lentis Research, Lentis Psychiatric Institute, P.O. Box 86, 9700 AB Groningen, The Netherlands \\ ' Department of Social and Organizational Psychology, Utrecht University, Heidelberglaan 1, 3584 CS Utrecht, The Netherlands \\ ${ }^{\mathrm{d}}$ Hanze University of Applied Sciences, School of Nursing, Master of Advanced Nursing Practice, Eyssoniusplein 18, 9714 CE Groningen, The Netherlands
}

\section{A R T I C L E I N F O}

\section{Article history:}

Received 30 October 2015

Received in revised form 11 February 2016

Accepted 18 February 2016

\section{Keywords:}

Attitude

Orientation

Nursing students

Recruitment

Survey

\begin{abstract}
A B S T R A C T
Background: Previous studies have identified various reasons for students to choose a career in nursing. Students at the start of their programme hold a great variety of images and perceptions of nursing which can affect their orientation and attitudes towards their future profession.

Objectives: This paper aims to examine nursing students' orientation and attitudes towards nursing at the beginning of their educational programme, and to explore predictors of positive orientation and attitudes.

Design: The study used a quantitative cross-sectional design.

Settings: A survey was conducted among first-year nursing students at four nursing universities of applied sciences in the Netherlands.

Participants: Questionnaires were administered to all students enrolled in a bachelor of nursing programme ( $\mathrm{n}=$ 1414) at these universities.

Methods: Respondents completed a survey consisting of: 1) Nursing Orientation Tool, 2) Nursing Attitude Questionnaire, and 3) demographic data such as gender, living status, nursing experience, preliminary training, first-choice programme, and career choice. Kruskal Wallis tests, with post hoc Mann Whitney U tests, were used to compare group scores. Multiple regression was performed to investigate predictors of positive orientation and attitudes towards nursing.

Results: Students in this study sample $(\mathrm{n}=1244)$ strongly agreed with statements related to caring, nursing expertise, professional nursing knowledge and the application of this knowledge. Predictors of positive orientation and attitudes towards nursing include having nursing/caring experience, indicating nursing as the first choice for study, preliminary vocational training, and a desire to make a career in nursing.

Conclusions: Data from this survey suggest a link between personal and environmental characteristics and motivations to select nursing as a career. Understanding which factors predict positive orientation and attitudes towards nursing could offer educators a tool in the recruitment and selection assessment of new students.
\end{abstract}

(c) 2016 Elsevier Ltd. All rights reserved.

\section{Introduction}

\subsection{Perceptions of Nursing and Career Choice}

There are several reasons why students choose nursing as a career, such as a desire to care for and work with sick people (Cook et al., 2003; Jirwe and Rudman, 2012), past healthcare work experience (Beck, 2000; Larsen et al., 2003), the expected career opportunities and the wide variety of available work the profession has to offer (Mooney et al., 2008; Vanhanen et al., 1999). The literature shows

\footnotetext{
* Corresponding author.

E-mail addresses: y.ten.hoeve@umcg.nl (Y. ten Hoeve), s.castelein@lentis.nl (S. Castelein),w.s.jansen@uu.nl (W. Jansen), gr.j.jansen@pl.hanze.nl (G. Jansen), p.f.roodbol@umcg.nl (P. Roodbol).
}

that the desire to care for others is one of the main motives for students to choose nursing as a career (Mooney et al., 2008; Phillips et al., 2015). Nursing is regarded as a profession in which the values of caring and helping others are central and the focus of all nursing activities (Day et al., 2005; O'Brien et al., 2008). Students choose nursing because they value a career involving altruism, intellectual challenges, goal attainment, and job security (Miers et al., 2007; Rhodes et al., 2011; Sand-Jecklin and Schaffer, 2006). The study by Phillips et al. (2015) revealed that student nurses at the beginning of their training are enthusiastic about the caring aspect of the profession and that they really aim to make a difference to people's lives.

Personal and environmental characteristics are closely linked to motivations of students to choose nursing and to complete their programme. It seems that nursing students begin their training with a fairly well-formed sense of their future profession, but past research 
also shows that there is a noticeable gap between expectations and the reality of the clinical learning environment (Magnussen and Amundson, 2003; Papathanasiou et al., 2014). Unrealistic expectations of nursing programmes can lead to dissatisfaction and voluntary withdrawal (Brodie et al., 2004; O'Donnell, 2011). As dropout rates of nursing students is a worldwide problem, it is of main importance to further investigate their orientation and attitudes and potential predictors of a positive outcome.

\subsection{Factors Influencing Students' Orientation and Attitudes Towards Nursing}

Despite the fact that the image of nursing is undergoing change, many stereotypes still remain which are influenced by a number of factors including society and the media (Bolan and Grainger, 2009; Mooney et al., 2008). Nursing is regarded as a profession undervalued by society, and which lacks academic training and intellectual depth (Brodie et al., 2004; O'Brien et al., 2008). It is not inconceivable that these images mark student perceptions of the nursing profession. Previous studies show that nursing students begin their programme with preconceived ideas and misconceptions about nursing and nurses (Brodie et al., 2004; Day et al., 2005; Happell, 1999). These perceptions can differ by gender, preliminary training and healthcare work experience. The studies of Cowin and Johnson (2011) and Miers et al. (2007), for example, showed significant differences in perceptions according to mode of entry and healthcare experience. Students with healthcare work experience were notably less focused on nurses being compassionate and more on aspects of the professional role of nurses. Other characteristics can also influence students' perceptions of nursing (Bolan and Grainger, 2009; Safadi et al., 2011; Vanhanen-Nuutinen et al., 2012). The study by Safadi et al. (2011) showed that students who said that nursing was their first choice demonstrated more positive perceptions of nursing.

With regard to education, the Netherlands underwent a radical change in healthcare education when the curriculum was reformed at the national level. Until 1971 the system of professional training of nurses had been based on the apprenticeship model; since then, nursing programmes have been linked to higher education institutions. In 2002 the Bologna agreement was concluded and the Bachelor's-Master's structure in higher education, including higher vocational education, was introduced. Professional values, nursing roles, nursing practice and clinical decision-making are some of the competence categories which comply with the Bologna agreement (Salminen et al., 2010). It is imperative therefore, that the perceptions of Dutch nursing students towards these concepts are verified.

\section{Objectives}

The aim of this study was twofold:

1) to examine what nursing students' orientation and attitudes towards nursing are at the beginning of their education

2) to explore which characteristics are the strongest predictors of positive orientation and attitudes towards nursing

\section{Methods}

\subsection{Study Design and Sample}

A cross-sectional survey design was used. Questionnaires were administered to all first-year students enrolled in a Bachelor of Nursing programme at four nursing universities of applied sciences in the Netherlands $(\mathrm{n}=1414)$.

\subsection{Instruments}

The Nursing Orientation Tool (Vanhanen et al., 1999) and the Nursing Attitude Questionnaire (Toth et al., 1998) were used. A forwards-backwards translation process was performed for both instruments to ensure content and semantic equivalence and applicability to the Dutch cultural context. The translator for the blind reverse translation was not involved in the project.

\subsection{The Nursing Orientation Tool (NOT)}

The Nursing Orientation Tool (Vanhanen et al., 1999) is a widelyused self-report instrument and consists of seventeen items using a five-point Likert scale. The instrument measures students' orientation to nursing using three subscales: caring, nursing expertise and life orientation. The caring orientation is based on 'students' meaningful caring and nursing experiences either in their families or in working life. The nursing expertise orientation is based on 'professional nursing experience'. The life orientation is based on 'the need to keep a balance between family life and studies' (Vanhanen and Janhonen, 2000b, p. 655). The validity and reliability of the tool were tested in previous studies (Janhonen et al., 2000; Vanhanen and Janhonen, 2000a).

\subsection{The Nursing Attitude Questionnaire (NAQ)}

This instrument was developed by Toth et al. (1998) and is one of the earliest tools measuring attitudes towards nursing. Attitude towards nursing was defined theoretically 'as the view that persons hold regarding the roles, values, and professional activities of nurses, and the responsibilities nurses have towards society' (Toth et al., 1998). The NAQ consists of a thirty-item questionnaire using a five-point Likert scale. The reliability of the NAQ was tested in previous studies (Bolan and Grainger, 2009; Grainger and Bolan, 2006; Toth et al., 1998). However, these studies used the scores across the entire NAQ to compare demographics or interventions, not content areas. No factor analysis was performed to test its construct validity. It is not clear which items contribute to which factor or dimension of the 'attitude towards nursing' concept. To reduce the NAQ items to a smaller number of coherent subscales, we submitted the questionnaire to closer inspection.

\subsection{Item Reduction and Factorial Testing of the NAQ}

A team of four researchers reviewed the NAQ items to verify that their wording reflected the concept measured: attitude towards nursing. The specific meaning of each item was examined to establish face validity. Twelve items were removed based on open discussions of the intended meaning and group consensus, resulting in eighteen items for inclusion for further analysis. Two core concepts were clearly differentiated: Nursing Agency and Advocacy \& Empathy. Nursing Agency can be regarded as the link between nursing science and nursing practice (Orem, 2001). Orem made the point that 'nurses must not only master such knowledge, that is, make the knowing their own, but also master its application in practice situation' (Orem, 2001, p. 16). Advocacy \& Empathy refers to the extent that nurses speak out and speak for patients, and act on the unmet needs of patients (Hanks, 2008; O'Connor and Kelly, 2005).

To test the factorial structure of the reduced NAQ an Exploratory Factor Analysis (EFA) was performed first. The results of the EFA revealed two measurable factors in the reduced NAQ. A Confirmatory Factor Analysis (CFA) was then conducted. The goodness-of-fit of the two factor solution was evaluated in the CFA using multiple criteria: chi-square $\left(\chi^{2}\right)$, chi-square/degrees of freedom $\left(\chi^{2} / d f\right)$ and root mean square error of approximation (RMSEA). The following goodness-of-fit indices were obtained for the two-factor model (with criteria for good fit in brackets): $\chi^{2} / d f=3.69(2.0-5.0)$, CFI $=0.90(>0.90)$, RMSEA $=$ 
$0.046(<0.06)$, NNFI $=0.87(>0.80)$. The Cronbach's alpha of the reduced NAQ (18 items) in this study was .79 . The reliability of the subscales ranged from good to acceptable: Nursing Agency (14 items $\alpha=.74$ ) and Advocacy \& Empathy (4 items; $\alpha=.63$ ). We considered the reduced NAQ suitable for further analyses based on these outcomes.

\subsection{Data Collection}

Arrangements were made with Deans and Faculty Boards of each nursing university to permit teachers to use $15 \mathrm{~min}$ of their classes to distribute and collect the questionnaires. The data were collected at the beginning of the programmes in September 2011.

\subsection{Data Analysis}

Comparisons were made using chi-square tests for categorical variables and the Spearman's Rank Order Correlation for the relationship between two continuous variables. The Kruskal Wallis tests, with post hoc Mann Whitney U tests, were used to compare group scores. Multiple regression was performed to test which of the characteristics was most predictive of positive orientation and attitudes towards nursing. Because some independent variables were not continuous, (first-choice programme, preliminary training, nursing/caring experience, and living status) dummies of these variables were constructed to perform the regression analysis.

\subsection{Ethical Considerations}

Deans and Faculty Boards of each university provided their permission for this study. The confidentiality of the study was guaranteed in the covering letter and the students were advised of the study's purpose. The respondents were informed in writing that participation in the study was voluntary, and that their responses would be analysed and published anonymously. Consent for participation was assumed for all questionnaires returned.

\section{Results}

\subsection{Demographics}

A total of 1244 completed questionnaires were returned, a response rate of $88 \%$. The majority ( $82 \%$ ) of the respondents were female. The mean age was 20 years (SD 4.3), with 77\% being between 17 and 20,

Table 1

Sociodemographic characteristics $(\mathrm{n}=1244)$

\begin{tabular}{lll}
\hline & $\%(\mathrm{n})$ & Mean $(\mathrm{SD})$ \\
\hline $\begin{array}{l}\text { Gender } \\
\text { Male }\end{array}$ & $18(221)$ & \\
Female & $82(1023)$ & \\
Age & & \\
& & \\
Preliminary training & $20(246)$ \\
Vocational & $80(997)$ \\
Non-vocational & $50(617)$ \\
Nursing/caring experience & \\
Past problems with programme. & $13(159)$ \\
Programme-related problems & $40(502)$ \\
Personal problems & $47(583)$ \\
Programme-related and personal problems & $67(825)$ \\
Nursing as first choice & \\
Career aspiration & $81(1001)$ \\
Nursing as a career & $16(198)$ \\
Other career & $3(45)$ \\
Do not know yet &
\end{tabular}

20\% between 21 and 30, and 3\% being 31 and older. See Table 1 for all the characteristics.

\subsection{Sociodemographic Associations}

Female students more often reported that nursing was their first choice than male students, $\chi^{2}(1, \mathrm{n}=1239)=10.56, \mathrm{p}=.001$. Male students had more often encountered problems with previous programmes than female students $\chi^{2}(1, \mathrm{n}=1243)=10.72, \mathrm{p}=$ .001 . Respondents who were living at home with their parents mentioned that nursing was their first-choice programme more often than respondents living independently, $\chi^{2}(1, \mathrm{n}=1236)=4.43, \mathrm{p}=.035$, they also faced more problems with previous programmes, $\chi^{2}(1, \mathrm{n}=$ $1240)=15.42, \mathrm{p}=.000$, and they had less nursing/caring experience $\chi^{2}(1, \mathrm{n}=1241)=36.78, \mathrm{p}=.000$. Students with preliminary vocational training reported more often that nursing was their firstchoice programme, $\chi^{2}(1, \mathrm{n}=1239)=8.31, \mathrm{p}=.004$. They also had more nursing/care experience than students with non-vocational preliminary training, $\chi^{2}(2, \mathrm{n}=1243)=31.58, \mathrm{p}=.000$. Students who reported that nursing was their first-choice programme also aimed to make a career in nursing. The difference with other students was significant $\chi^{2}(2, \mathrm{n}=1239)=99.04, \mathrm{p}=.000$. Finally, a significant association was found between students with nursing/caring experience and their aim to make a career in nursing, $\chi^{2}(2, n=$ $1244)=14.36, \mathrm{p}=.001$.

\subsection{Orientation to Nursing: Caring, Nursing Expertise and Life Orientation (NOT)}

The results from the closed questions demonstrated that most students agreed with statements related to the caring orientation scale and the nursing expertise orientation scale. The life orientation scale showed that this group of students scored low on the items which reflect problems with finding a balance between their studies and private life. The highest scores are displayed in bold (Table 2).

The results of the non-parametric tests revealed that female tudents agreed more with statements related to caring and life orientation, while males scored higher on nursing expertise. Students for whom nursing was the first-choice programme agreed more with the statements related to the caring orientation and the nursing expertise scale items than students who had initially chosen another programme. Preliminary vocational training had a positive influence on the students' orientation to caring, nursing expertise and life orientation. Students with nursing/caring experience showed a more positive orientation to caring and nursing expertise than students who did not have nursing/ caring experience. Respondents who aimed to make a career in nursing had a more positive orientation to caring and to nursing expertise than their counterparts who were seriously considering a career change. Finally, students who lived independently had a more positive orientation towards their future profession compared to students living at home with their parents (Table 3).

\subsection{Predictors of a Positive Orientation Towards Nursing}

Five variables proved to be predictors of a more positive orientation towards nursing. Being a male student was a predictor of a more positive orientation towards nursing expertise; females agreed more with statements related to the life orientation scale. Choosing nursing as a first-choice programme and having preliminary vocational training were predictors of a more positive orientation towards nursing and the caring orientation. Having nursing/caring experience and choosing a career in nursing predicted a more positive orientation towards caring and nursing expertise (Table 4). 
Table 2

Survey responses for 'caring orientation', 'nursing expertise' and 'life orientation'.

\begin{tabular}{|c|c|c|c|c|c|c|}
\hline $\mathrm{N}=1244$ & $\begin{array}{l}\mathrm{TA} \\
\%\end{array}$ & $\begin{array}{l}\text { A } \\
\%\end{array}$ & $\begin{array}{l}\mathrm{N} \\
\%\end{array}$ & $\begin{array}{l}\mathrm{D} \\
\%\end{array}$ & $\begin{array}{l}\text { TD } \\
\%\end{array}$ & $\mathrm{M}^{\mathrm{a}}$ \\
\hline \multicolumn{7}{|l|}{ Caring orientation scale } \\
\hline 1. I've dreamt of becoming a nurse since I was a child & 6.3 & 17.3 & 19.6 & 31.7 & 25.1 & 2.48 \\
\hline 2. Nursing is a calling & 5.7 & 41.0 & 37.2 & 12.3 & 3.8 & 3.32 \\
\hline 3. A nurse must have a powerful need to take care for others & 44.2 & 51.2 & 2.9 & 1.4 & 0.3 & 4.38 \\
\hline 4. It is important to me that I get to study nursing & 22.2 & 59.9 & 14.8 & 2.6 & 0.5 & 4.01 \\
\hline 5. Working as a nurse gives my life a meaningful content & 14.3 & 51.7 & 27.9 & 4.8 & 1.3 & 3.37 \\
\hline 6. I expect, as a nurse I have an opportunity to develop as a person & 25.3 & 59.8 & 11.6 & 2.3 & 0.9 & 4.06 \\
\hline \multicolumn{7}{|l|}{ Nursing expertise orientation scale } \\
\hline 1. I chose nursing because of the variety of jobs available & 38.3 & 44.2 & 8.6 & 6.5 & 2.3 & 4.10 \\
\hline 2. I am confident I will become a good nurse & 26.3 & 60.9 & 11.8 & 0.8 & 0.3 & 4.12 \\
\hline 3. One of the most important qualities of a nurse is mental strength & 20.2 & $\mathbf{5 9 . 0}$ & 18.2 & 2.3 & 0.3 & 3.96 \\
\hline 4. In nursing, I can choose my working field according to my personal interests & 35.2 & 53.0 & 9.4 & 1.9 & 0.6 & 4.20 \\
\hline 5. I expect this training to give me a possibility to progress in my career & 24.4 & 54.6 & 17.9 & 2.5 & 0.6 & 4.00 \\
\hline 6. In nursing, I can learn to understand myself and others better than in some other professions & 8.3 & 39.3 & 40.4 & 10.9 & 1.1 & 3.43 \\
\hline \multicolumn{7}{|l|}{ Life orientation scale } \\
\hline 1. I would not have started studying nursing here if it. had meant moving away from my family & 2.7 & 10.6 & 27.8 & 42.5 & 16.4 & 2.41 \\
\hline 2. I would have applied to study here earlier but it was not possible because of where my family was living & 1.4 & 0.4 & 9.2 & 21.3 & 67.8 & 1.46 \\
\hline 3. My studying is dependent on the financial situation in my family & 3.4 & 11.6 & 14.8 & 29.2 & 41.0 & 2.07 \\
\hline $\begin{array}{l}\text { 4. I applied to study nursing, because I was unemployed/ } \\
\text { going to be unemployed }\end{array}$ & 1.5 & 1.2 & 3.0 & 14.3 & 79.9 & 1.30 \\
\hline 5. I do not want to make decisions in my life that would risk my family being together & 13.7 & 23.2 & 33.8 & 13.2 & 16.2 & 3.05 \\
\hline
\end{tabular}

$\mathrm{TA}=$ totally agree (5); $\mathrm{A}=$ agree (4); $\mathrm{N}=$ do not have an opinion (3); $\mathrm{D}=$ disagree (2); $\mathrm{TD}=$ totally disagree (1).

a $\mathrm{M}=$ mean total score (range 1.0-5.0)

\subsection{Attitude Towards Nursing: Nursing Agency and Advocacy \& Empathy} (NAQ)

The NAQ demonstrates that students agreed with all items on the advocacy \& empathy subscale and with most items on the nursing agency subscale. The highest scores are displayed in bold (Table 5).

The results of the non-parametric tests showed that males scored higher on items on the nursing agency subscale. Students for whom nursing was the first-choice programme agreed more with statements related to advocacy \& empathy. Students with nursing/caring experience scored higher on the overall NAQ and on nursing agency than students without nursing/caring experience. With regard to overall NAQ scores, the same applies to students who lived independently compared to students living at home with their parents. However, they agreed less with statements related to advocacy \& empathy (see Table 6).

\subsection{Predictors of Positive Attitudes Towards Nursing}

With respect to the NAQ four independent variables turned out to predict more positive attitudes. Being a male student, having nursing/ caring experience, and living independently turned out to be predictors of more positive attitudes towards nursing agency. Having nursing as first-choice programme was a predictor of more positive attitudes towards advocacy \& empathy (Table 7).

\section{Discussion}

The first aim of this study was to explore the orientation and attitudes of nursing students towards nursing at the beginning of their programme. The results showed that respondents generally strongly agreed with statements related to caring, nursing expertise, nursing agency and advocacy \& empathy. Protecting and caring for patients, future career opportunities, integrating nursing research into clinical practice and participating in healthcare policies turned out to be important issues. In addition, the students felt it important to study nursing and to have the opportunity to develop as people and professionals. They also believed that the service provided by nurses is as important as that provided by physicians. With regard to the second aim, the findings indicate that a more positive orientation and attitude towards nursing was predicted by personal and environmental characteristics such as gender, living status, having indicated nursing as first-choice programme, starting the nursing programme having completed preliminary vocational training, having nursing/caring experience, and aiming to make a career in nursing.

Previous studies have been conducted to evaluate student motivation to choose a career in nursing. In the study by Jirwe and Rudman (2012) approximately 75\% of the respondents wanted to care for and help others. This is consistent with our findings. The studies by Bolan and Grainger (2009) and Grainger and Bolan (2006) also show that beginner students have a quite positive image of nursing, and that

Table 3

Personal and environmental characteristics and factor scores on orientation.

\begin{tabular}{|c|c|c|c|c|c|c|c|c|c|c|c|c|}
\hline \multirow[t]{2}{*}{ Scale } & \multicolumn{2}{|l|}{ Gender } & \multicolumn{2}{|c|}{$\begin{array}{l}\text { Nursing as } 1 \text { st } \\
\text { choice }\end{array}$} & \multicolumn{2}{|c|}{ Vocational training } & \multicolumn{2}{|c|}{ Nursing experience } & \multicolumn{2}{|c|}{$\begin{array}{l}\text { Nursing career } \\
\text { choice }\end{array}$} & \multicolumn{2}{|c|}{ Living status } \\
\hline & $\mathrm{z}$ & $\mathrm{p}$ & $z$ & $\mathrm{p}$ & $z$ & $\mathrm{p}$ & $z$ & $\mathrm{p}$ & $z$ & $\mathrm{p}$ & $z$ & $\mathrm{p}$ \\
\hline Not & -.931 & .352 & -4.81 & $.000^{* *}$ & -4.40 & $.000^{* *}$ & -4.65 & $.000^{* *}$ & -6.45 & $.000^{* *}$ & -2.09 & $.036^{*}$ \\
\hline Caring & -2.70 & $.007^{* *}$ & -6.90 & $.000^{* *}$ & -3.06 & $.002^{* *}$ & -4.37 & $.000^{* *}$ & -7.08 & $.000^{* *}$ & -1.24 & .214 \\
\hline Nursing expertise & -3.18 & $.001^{* *}$ & -2.32 & $.020^{*}$ & -2.44 & $.015^{*}$ & -3.12 & $.002^{* *}$ & -5.07 & $.000^{* *}$ & -1.16 & .247 \\
\hline Life orientation & -2.46 & $.014^{*}$ & -.126 & .900 & -2.31 & $.021^{*}$ & -.541 & .588 & -.601 & .548 & -1.69 & .091 \\
\hline
\end{tabular}

* $\mathrm{p}$-Value becomes significant at 0.05 .

** p-Value becomes significant at 0.01 . 
Table 4

Predictors of a positive orientation to nursing.

\begin{tabular}{|c|c|c|c|c|c|c|c|c|c|c|c|}
\hline \multirow[t]{2}{*}{ Scale } & \multicolumn{2}{|c|}{ Gender } & \multicolumn{2}{|c|}{ Nursing as 1 st choice } & \multicolumn{2}{|c|}{$\begin{array}{l}\text { Vocational } \\
\text { training }\end{array}$} & \multicolumn{2}{|c|}{$\begin{array}{l}\text { Nursing } \\
\text { experience }\end{array}$} & \multicolumn{2}{|c|}{$\begin{array}{l}\text { Nursing career } \\
\text { choice }\end{array}$} & \multirow[b]{2}{*}{$\mathrm{R}^{2}$} \\
\hline & $\beta$ & $\mathrm{p}$ & $\beta$ & $\mathrm{p}$ & $\beta$ & $\mathrm{p}$ & $\beta$ & $\mathrm{p}$ & $\beta$ & $\mathrm{p}$ & \\
\hline NOT & & & .10 & $.001^{* *}$ & .08 & $.017^{*}$ & .10 & $.000^{* *}$ & & & .08 \\
\hline Caring & & & .14 & $000^{* *}$ & .06 & $.025^{*}$ & .10 & $.001^{* *}$ & .14 & $.000^{* *}$ & .09 \\
\hline Nursing expertise & .09 & $.002^{* *}$ & & $.020^{*}$ & & & .08 & $.009^{* *}$ & .14 & $.000^{* *}$ & .04 \\
\hline Life orientation & .06 & $.027^{*}$ & & .900 & & & & & & & .02 \\
\hline
\end{tabular}

* p-Value becomes significant at 0.05 .

** p-Value becomes significant at 0.01 .

they believe in the importance of nursing research and nurses' role in policy development. With respect to career, students in our study chose nursing because of the variety of jobs available, the field which matches their personal interests, and the opportunities offered for career progression. These results also strengthen those of previous studies (Jirwe and Rudman, 2012; Larsen et al., 2003; Rognstad et al., 2004). Across the whole sample, the life orientation scale scores were the lowest, indicating that this group of students did not experience problems with finding a balance between their studies and private life/family. In contrast, the studies by Vanhanen and Janhonen (2000a) found that life orientation was the most dominant orientation in nursing. This could be because this study was conducted in Finland, where the distance between work location and family was one of the determining factors for registering for a particular programme (Vanhanen and Janhonen, 2000a; Vanhanen-Nuutinen et al., 2012).

Our study found significant gender differences. Males scored higher on nursing expertise and nursing agency, both domains reflecting the roles and professionalism of nursing. Females agreed more with statements related to life orientation, and finding a balance between studies and private life. These differences can be explained by traditional gender differences which remain prevalent, even in Western cultures. The gender differences in Israeli nursing students in the study by Toren et al. (2012) also showed that proximity of living arrangements to the workplace was more important to females, as well as transportation to and from work. Cowin and Johnson (2011) found that males rated lower for caring on the Qualities of Nursing (QoN) scale which examines the qualities of professional nurses. Male students in the study by Zysberg and Berry (2005) placed greater emphasis on aspects such as leadership and advancement, while females paid more attention to a perceived fit between themselves and the profession of nursing (Zysberg and Berry, 2005). In our study, previous nursing/caring experience proved to be the most important factor of influence on positive orientation and attitudes towards nursing. This corresponds with the results of the study by Pryjmachuk et al. (2009), who found that students with more experience were more likely to choose a career in nursing and complete their programme. Larsen et al. (2003) and Miers et al. (2007) also found that past healthcare work experience was a motivating factor for choosing a career in nursing. Students with nursing experience also seemed to have more insight into the reality of working with patients. This is congruent with Cowin and Johnson's (2011) findings that students with healthcare experience were more focused on aspects of the role and professional issues of nursing. Students for whom nursing was the first-choice programme turned out to be more positively oriented towards nursing, especially the caring orientation. They also agreed more with advocacy \& empathy issues. This can be related to the results from previous studies which showed that the desire to care for others is one of the main motives for students choosing a career in nursing (Mooney et al., 2008; Phillips et al., 2015). Interestingly, the studies by Safadi et al. (2011) and Salamonson et al. (2014) showed that students for whom nursing was the first choice were more likely to continue their educational nursing programme. In our study, having completed preliminary vocational training was a predictor of a positive orientation towards nursing and the caring dimension. From this we can assume that these students had already chosen vocational training or a caring profession before starting nursing training. This finding, however, is inconsistent with the study by Miers et al. (2007), who found that students with vocational training gave fewer altruistic reasons for choosing nursing as a career

Table 5

Survey responses for 'nursing agency' and 'advocacy \& empathy'.

\begin{tabular}{|c|c|c|c|c|c|c|}
\hline $\mathrm{N}=1244$ & $\begin{array}{l}\text { SA } \\
\%\end{array}$ & $\begin{array}{l}\text { A } \\
\%\end{array}$ & $\begin{array}{l}\mathrm{U} \\
\%\end{array}$ & $\begin{array}{l}\mathrm{D} \\
\%\end{array}$ & $\begin{array}{l}\text { SD } \\
\%\end{array}$ & $\mathrm{M}^{\mathrm{a}}$ \\
\hline \multicolumn{7}{|l|}{ Nursing agency scale } \\
\hline 1. Nurses consistently update their practice in relation to current health trends & 17.8 & 62.6 & 17.7 & 1.7 & 0.2 & 3.96 \\
\hline 2. It takes intelligence to be a nurse & 13.2 & 56.8 & 22.6 & 6.9 & 0.5 & 3.75 \\
\hline 3. Nurses should have a baccalaureate degree for entrance into practice & 8.5 & 26.7 & 34.5 & 26.3 & 4.1 & 3.09 \\
\hline 4. Nurses with advanced degrees make important contributions to patient care & 11.0 & 40.7 & 40.3 & 6.9 & 1.1 & 3.54 \\
\hline 5. Nurses are capable of independent practice & 35.2 & 56.9 & 5.3 & 2.0 & 0.6 & 4.24 \\
\hline 6. The service given by nurses is as important as that given by physicians & 39.5 & 50.5 & 5.7 & 3.2 & 1.1 & 4.24 \\
\hline 7. Research is vital to nursing as a profession & 18.8 & 60.2 & 19.8 & 1.0 & 0.2 & 3.96 \\
\hline 8. Nurses participate in the development of health care policies & 28.7 & 63.8 & 6.3 & 1.0 & 0.2 & 4.20 \\
\hline 9. Nurses act as resource persons for individuals with health problems & 20.7 & 61.4 & 13.5 & 3.7 & 0.6 & 3.98 \\
\hline 10. Nurses integrate health teaching into their practice & 6.1 & 59.5 & 32.8 & 1.3 & 0.2 & 3.70 \\
\hline 11. Nurses speak out against inadequate working conditions & 11.9 & 44.7 & 40.9 & 2.5 & ---- & 3.66 \\
\hline 12. Nurses follow the physician's orders without questions & 1.5 & 6.6 & 15.6 & 57.4 & 18.9 & 3.86 \\
\hline 13. Nurses incorporate research findings into their clinical practice & 13.0 & 60.5 & 23.9 & 2.3 & 0.2 & 3.84 \\
\hline 14. The major goal of nursing research is to improve patient care & 21.7 & 59.3 & 14.9 & 3.4 & 0.6 & 3.98 \\
\hline \multicolumn{7}{|l|}{ Advocacy E' empathy scale } \\
\hline 1. Nurses are patient's advocates & 23.2 & 61.1 & 13.0 & 2.7 & 0.1 & 4.05 \\
\hline 2. Nurses protect patients in the health care system & 23.2 & 64.7 & 10.1 & 2.0 & 0.1 & 4.09 \\
\hline 3. Nurses in general are kind, compassionate human beings & 20.7 & 60.4 & 14.6 & 3.6 & 0.6 & 3.97 \\
\hline 4. Nurses value time at the bedside caring for patients & 22.0 & 67.5 & 8.7 & 1.5 & 0.3 & 4.09 \\
\hline
\end{tabular}

SA = strongly agree (5); A = agree (4); $\mathrm{U}=$ uncertain (3); D = disagree (2); SD = strongly disagree (1).

a $\mathrm{M}=$ mean total score (range 1.0-5.0). 
Table 6

Personal and environmental characteristics and factor scores on attitudes.

\begin{tabular}{|c|c|c|c|c|c|c|c|c|}
\hline \multirow[t]{2}{*}{ Scale } & \multicolumn{2}{|l|}{ Gender } & \multicolumn{2}{|c|}{$\begin{array}{l}\text { Nursing as } 1 \text { st } \\
\text { choice }\end{array}$} & \multicolumn{2}{|c|}{$\begin{array}{l}\text { Nursing } \\
\text { experience }\end{array}$} & \multicolumn{2}{|c|}{ Living status } \\
\hline & z & $\mathrm{p}$ & $z$ & $\mathrm{p}$ & $z$ & $\mathrm{p}$ & $z$ & $\mathrm{p}$ \\
\hline NAQ & -1.69 & .091 & -.415 & .678 & -2.42 & $.016^{*}$ & -2.23 & $.026^{*}$ \\
\hline $\begin{array}{l}\text { Nursing } \\
\text { agency }\end{array}$ & -2.17 & $.030^{*}$ & -.407 & .684 & -2.89 & $.004^{* *}$ & -3.59 & $.000^{* *}$ \\
\hline $\begin{array}{c}\text { Advocacy \& } \\
\text { empathy }\end{array}$ & -.020 & .984 & -2.56 & $.010^{*}$ & -.328 & .743 & -2.01 & $.045^{*}$ \\
\hline
\end{tabular}

than those without. Our study demonstrated that students who aimed for a non-nursing career agreed less with statements related to caring and to nursing expertise. Having an ambition to make a career in nursing seemed to predict a positive perception of both the caring and the professional dimensions of nursing.

The results of the statistical analyses showed significant differences between group scores on orientation and attitudes towards nursing. However, the explained variance of the predictors was low. In this study we did not include independent variables such as role models and the students' own experiences as patients. The studies by Larsen et al. (2003) and Lai et al. (2006) showed that these variables positively influence student perceptions of nursing. Including these variables could increase the explained variance of the predicting factors. Nevertheless, the results of this study showed statistically significant predictors, from which important conclusions can be drawn about how predictor values are associated with orientation and attitudes of nursing students. Additional qualitative research might give more insight into, yet unknown, explanatory variables. However, studies on human attitudes show in general quite low R-squared values (Fichman, 1999; Frost, 2013).

\subsection{Study Strengths and Limitations}

The strength of this study is its large sample and high response rate (88\%), representing $32 \%$ of all first-year nursing students registered for a bachelor of nursing programme in the Netherlands in September 2011. This large sample implies high representativeness for the target population and therefore good generalizability of the findings to other student populations. The reduced version of the Nursing Attitude Questionnaire needs further psychometric testing. The reliability of the subscales ranged from good to acceptable, implying that the validity and reliability of the instrument should be tested further. However, both instruments (the NOT and the NAQ) are commonly used in nursing research to investigate the perceptions of nursing students.

\section{Conclusions}

With this study we aimed to gain insight into issues related to nursing students' orientation and attitudes towards nursing, to enable us to derive tools to achieve desired or even necessary changes in education and the curriculum. The students' agreement with statements related to nursing expertise and nursing agency, such as

Table 7

Predictors of a positive attitude towards nursing.

\begin{tabular}{llllll}
\hline Scale & Gender & $\begin{array}{r}\text { Nursing as } \\
\text { 1st choice }\end{array}$ & $\begin{array}{l}\text { Nursing } \\
\text { experience }\end{array}$ & $\begin{array}{l}\text { Living } \\
\text { status }\end{array}$ & $\mathrm{R}^{2}$ \\
\hline Nursing agency & $\begin{array}{l}\beta=.07 \\
\mathrm{p}=.018^{*}\end{array}$ & $\begin{array}{l}\beta=.07 \\
\mathrm{p}=.023^{*}\end{array}$ & $\begin{array}{l}\beta=.07 \\
\mathrm{p}=.010^{* *}\end{array}$ & .02 \\
$\begin{array}{c}\text { Advocacy \& } \\
\text { empathy }\end{array}$ & & $\beta=.07$ & & .01 \\
\hline
\end{tabular}

\footnotetext{
${ }^{*}$ p-Value significant at the 0.05 level.
}

** p-Value significant at the 0.01 level. mastering knowledge and its application in practice, are in line with the professional value, roles, nursing practice and clinical decisionmaking competence categories of the Bologna agreement. This could indicate that the perceptions of this cohort of students of these concepts are very positive and professional. A positive attitude is a prerequisite for effective learning. Professional orientation has also been linked to the students' study performance, learning motivation and satisfaction (Vanhanen and Janhonen, 2000a, 2000b). The importance of preconceptions in the context of learning a profession should not be underestimated. Understanding nursing students' orientations and attitudes towards nursing offers educators the opportunity to prepare them better for their future profession.

\section{Recommendations}

Experience in a healthcare setting influences students' career decision-making, and has been found to be one of the predictors of positive orientation and attitudes towards nursing. Therefore, it is imperative that students are provided with opportunities to interact with professional nurses at an early stage in their programme. Preliminary vocational training, indicating that nursing is the student's firstchoice and wanting to make a career in nursing also predict positive orientation and attitudes towards nursing. This could be important in recruitment and selection interviews with new students to understand early commitment to nursing. A strong orientation and attitude towards nursing, combined with personal interest, could provide strong motivation for remaining in a programme and thus reduce student dropout in the early years of nursing training. More longitudinal research is required to investigate students' changing perceptions of nursing, linked to decisions to remain in or withdraw from nursing programmes.

\section{Funding}

No external funding.

\section{Conflict of interest}

None.

\section{Acknowledgements}

The authors thank the students, deans and faculty boards at Avans University of Applied Sciences, the Hanze University of Applied Sciences, the University of Applied Sciences Utrecht and the HAN University of Applied Sciences.

\section{Appendix A. Supplementary data}

Supplementary data to this article can be found online at http://dx. doi.org/10.1016/j.nedt.2016.02.019.

\section{References}

Beck, C.T., 2000. The experience of choosing nursing as a career. J. Nurs. Educ. 39 (7), 320-322.

Bolan, C., Grainger, P., 2009. Students in the BN program - do their perceptions change? Nurse Educ. Today 29 (7), 775-779.

Brodie, D.A., Andrews, G.J., Andrews, J.P., Thomas, G.B., Wong, J., Rixon, L., 2004. Perceptions of nursing: confirmation, change and the students experience. Int. J. Nurs. Stud. 41 (7), 721-733.

Cook, T.H., Gilmer, M.J., Bess, C.J., 2003. Beginning students' definitions of nursing: an inductive framework of professional identity. J. Nurs. Educ. 42 (7), 311-317.

Cowin, L.S., Johnson, M., 2011. Many paths lead to nursing: factors influencing students perceptions of nursing. Int. Nurs. Rev. 58 (4), 413-419.

Day, R.A., Field, P.A., Campbell, I.E., Reutter, L., 2005. Students' evolving beliefs about nursing: from entry to graduation in a four-year baccalaureate programme. Nurse Educ. Today 25 (8), 636-643.

Fichman, M., 1999. Variance Explained: Why Size Does Not (Always) Matter. In: Sutton, R.I., Staw, B.M. (Eds.), Research in Organizational Behavior vol. 21. Elsevier Science/ JAI Press, US, pp. 295-331. 
Frost, J., 2013. Regression Analysis: How Do I Interpret R-squared and Assess the Goodness-of-Fit? (Blog.minitab.com. Accessed on February 1st, 2016)

Grainger, P., Bolan, C., 2006. Perceptions of nursing as a career choice of students in the baccalaureate nursing program. Nurse Educ. Today 26 (1), 38-44.

Hanks, R.G., 2008. The lived experience of nursing advocacy. Nurs. Ethics 15 (4), 468-477.

Happell, B., 1999. When I grow up I want to be a ...? Where undergraduate student nurses want to work after graduation. J. Adv. Nurs. 29 (2), 499-505.

Janhonen, S., Vanhanen, L., Atwood, J., 2000. Developing and testing a cognitive orientation to nursing measurement tool. Vård I Norden 21 (56), 71-76.

Jirwe, M., Rudman, A., 2012. Why choose a career in nursing? J. Adv. Nurs. 68 (7), $1615-1623$.

Lai, H.L., Peng, T.C., Chang, F.M., 2006. Factors associated with career decisions in Taiwanese nursing students: a questionnaire survey. Int. J. Nurs. Stud. $43(-)$, 581-588.

Larsen, P.D. McGill, J.S., Palmer, S.J. 2003. Factors influencing career decisions: perspec tives of nursing students in three types of programs. J. Nurs. Educ. 42 (4), 168-173.

Magnussen, L., Amundson, M.J., 2003. Undergraduate nursing student experience. Nurs. Health Sci. 5 (4), 261-267.

Miers, M.E., Rickaby, C.E., Pollard, K.C., 2007. Career choices in health care: is nursing a special case? A content analysis of survey data. Int. J. Nurs. Stud. 44 (7), 1196-1209.

Mooney, M., Glacken, M., O'Brien, F., 2008. Choosing nursing as a career: a qualitative study. Nurse Educ. Today 28 (3), 385-392.

O'Brien, F., Mooney, M., Glacken, M., 2008. Impressions of nursing before exposure to the field. J. Clin. Nurs. 17 (14), 1843-1850.

O'Connor, T., Kelly, B., 2005. Bridging the gap: a study of general nurses' perceptions of patient advocacy in Ireland. Nurs. Ethics 12, 453-467.

O'Donnell, H., 2011. Expectations and voluntary attrition in nursing students. Nurse Educ. Pract. 11 (1), 54-63.

Orem, D.E., 2001. Nursing Concepts of Practice. sixth ed. Mosby, St. Louis

Papathanasiou, I.V., Tsaras, K., Sarafis, P., 2014. Views and perceptions of nursing students on their clinical learning environment: teaching and learning. Nurse Educ. Today 34 (1), 57-60.

Phillips, J., Cooper, K., Rosser, E., Scammell, J., Heaslip, V., White, S., Donaldson, I., Jack, E., Hemingway, A., Harding, A., 2015. An exploration of the perception of caring held by students entering nursing programmes in the United Kingdom: a longitudinal qualitative study phase 1. Nurse Educ. Pract. http://dx.doi.org/10.1016/j.nepr.2015.05.004.
Pryjmachuk, S., Easton, K., Littlewood, A., 2009. Nurse education: factors associated with attrition. J. Adv. Nurs. 65 (10), 149-160.

Rhodes, M.K., Morris, A.H., Lazenby, R.B., 2011. Nursing at its best: competent and caring. Online J. Nurs. Issues 16 (2). http://dx.doi.org/10.3912/OJIN.Vol16No02PPT01.

Rognstad, M.K., Aasland, O., Granum, V., 2004. How do nursing students regard their future career? Career preferences in the postmodern society. Nurse Educ. Today 24 (7), 493-500.

Safadi, R.R., Saleh, M.Y.N., Nassar, O.S., Amre, H.M., Froelicher, E.S., 2011. Nursing students' perceptions of nursing: a descriptive study of four cohorts. Int. Nurs. Rev. 58 (4), 420-427.

Salamonson, Y., Everett, B., Cooper, M., Lombardo, L., Weaver, R., Davidson, P.M., 2014 Nursing as first choice predicts nursing program completion. Nurse Educ. Today 34, 127-131.

Salminen, L., Stolt, M., Saarikosi, M., Suikkala, A., Vaartio, H., Leino-Kilpi, H., 2010. Future challenges for nursing education - a European perspective. Nurse Educ. Today 30 (3), 233-238.

Sand-Jecklin, K.E., Schaffer, A.E., 2006. Nursing students' perceptions of their chosen profession. Nurs. Educ. Perspect. 27 (3), 130-135.

Toren, O., Zelker, R., Port, N., 2012. Preferences of Israeli nursing students in choosing their future workplace. J. Nurs. Manag. 20 (1), 45-55.

Toth, J.C., Dobratz, M.A., Boni, M.S., 1998. Attitude toward nursing of students earning a second degree and traditional baccalaureate students: are they different? Nurs. Outlook 46 (6), 273-278.

Vanhanen, L., Janhonen, S., 2000a. Factors associated with students' orientations to nursing. J. Adv. Nurs. 31 (5), 1054-1062.

Vanhanen, L., Janhonen, S., 2000b. Changes in nursing students' orientations to nursing during education. Nurse Educ. Today 20 (8), 654-661.

Vanhanen, L., Hentinen, M., Janhonen, S., 1999. Students' orientations to nursing at the beginning of nursing education. Nord. J. Nurs. Res. Clin. Stud./Vẳrd I Norden 19 (3), $18-23$.

Vanhanen-Nuutinen, L., Janhonen, S., Maunu, M., Laukkala, H., 2012. Changes in Finnish nursing students' between mid-1990s and mid-2000s. Nurse Educ. Today 32 (5), 490-496.

Zysberg, L., Berry, D.M., 2005. Gender and students' vocational choices in entering the field of nursing. Nurs. Outlook 53 (4), 193-198. 